\title{
TRIPPING THE LIGHT FANTASTIC: USING LIGHT-BASED TECHNIQUES TO DIGITALLY DOCUMENT MEGALITHIC ARCHITECTURE
}

\author{
Eimear Meegan ${ }^{1}$, Maurice Murphy ${ }^{1}$, Anthony Corns ${ }^{2}$, Rob Shaw ${ }^{2}$, Clíodhna Ní Lionáin ${ }^{3}$, Garrett Keenaghan ${ }^{4}$ \\ ${ }^{1}$ Virtual Building Lab, Ireland, eimear.meegan@gmail.com \\ ${ }^{2}$ The Discovery Programme, Ireland, anthony@discoveryprogramme.ie \\ ${ }^{3}$ Devinish Nutrition, Ireland, cliodhna.nilionain@devenishnutrition.com \\ ${ }^{4}$ TU Dublin, Ireland, garrett.keenaghan@tudublin.ie
}

\section{Commission II}

KEY WORDS: iPad LiDAR, Artec Leo structured light scammer, photogrammetry, BIM, megalithic architecture

\begin{abstract}
This paper presents and discusses the preliminary results of a small scale visualisation project as part of which the low-cost LiDAR scanner that now comes as standard with the iPad Pro was used in conjunction with both the Arctec Leo structured light scanner and photogrammetric survey methods to record, analyse and present the recently excavated remains of a Neolithic passage tomb at Dowth Hall, Co, Meath, Ireland. It considers the ease and speed with which the small to medium scale structural components found here can be scanned or photographed, meshed, and textured using each approach and further explores whether the outputs produced in each case might be used to support and enhance each other.
\end{abstract}

\section{INTRODUCTION}

Photogrammetry, LiDAR and other 3D scanning techniques, have, of course, long served as invaluable tools within the field of cultural heritage research, conservation, and dissemination (El-Hakim et al. 2008; Remondino et al. 2012; Cerrillo et al. 2021). Indeed, Ireland's UNESCO World Heritage-inscribed Brú na Bóinne landscape, which is the focus of the current study, has received a variety of $3 \mathrm{D}$ treatments over the last decade (Eogan and Cleary, 2017). Aerial LiDAR, for example, has been extensively employed here for the purposes of visualising known monuments as well as identifying and cataloguing previously unrecorded sites (Davis et al., 2010; 2013; Corns and Shaw, 2013; Megarry and Davis, 2013). Terrestrial laser scanning and photogrammetry have, furthermore, been used to model both the exterior and interior megalithic architecture of the landscape's three largest Neolithic passage tombs at Newgrange, Knowth and Dowth (Davis et al., 2012; 3D Icons, 2015). In the case of the current project, however, the use of Apple's recently introduced LiDAR technology to digitally document the excavated remains of a smaller passage tomb at Dowth Hall represents the first recorded use of a low-cost scanner in this area. The question is whether such low-cost technology can make a valuable contribution to the visualisation, analysis and presentation of Brú na Bóinne's built heritage. In addressing this issue, the use of more costly and established survey methods, namely photogrammetry and structured light scanning by means of a dedicated instrument, will also be considered here, with a view to exploring whether the outputs produced in each case might be used to support and enhance each other.

\section{CASE STUDY CONTEXT}

\subsection{The Megalithic Tradition in Ireland}

Spanning some 2,000 years (c. 4,000-2,000 BC), Ireland's megalithic construction tradition arguably represents the most impressive material expression of the island's rich and complex tapestry of Neolithic ritual practice. This category of evidence comprises the remains of approximately 1,600 tombs, among which four major, morphologically defined classes have been identified, namely court, dolmen, passage and wedge tombs. The largest and most sophisticated of these structures belong to the passage tomb class, of which an estimated 237 examples have been recorded to date. As its name suggests, the defining characteristic of this tomb type is the presence of a stone built passageway through which a similarly constructed chamber is accessed (Figure 1). Both are usually covered by a circular mound of cairn stones or earth, or a mixture of both. In some instances, two passages, each leading to a chamber are contained within a single mound, and often the perimeter, which can range from $10 \mathrm{~m}$ to $90 \mathrm{~m}$ in diameter, is delineated by a kerb of contiguous megaliths or kerbstones. The interior structures are built using uprights or orthostats to form the walls, with transverse lintel stones used to roof the passages. Larger cap stones are frequently used to cover the chambers, though multicourse corbelled vaulted roofs, some of great height and complex engineering, are also known (Figure 2).

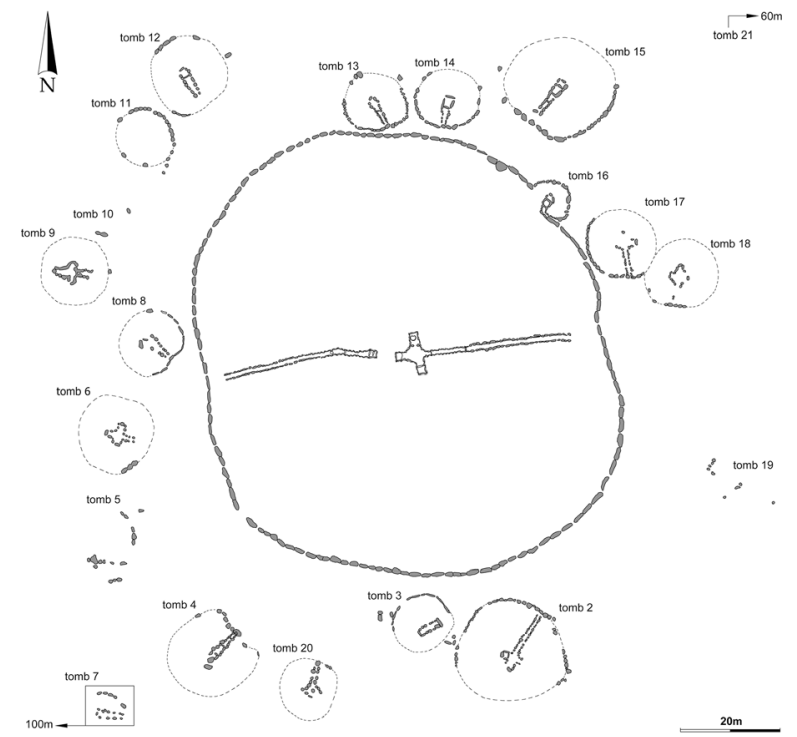

Figure 1. A plan view of the passage tomb cemetery at Knowth, Co. Meath, showing the focal mound, Site 1, surrounded by 20 smaller or satellite tombs (after Eogan and Cleary, 2017, Figure 2.1). 


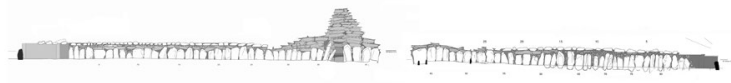

- लmim

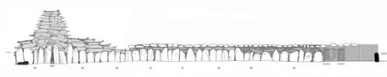

Figure 2. Elevation drawings of the eastern and western tombs contained within Site 1 at Knowth, Co. Meath (after Eogan and Cleary, 2017, Figure 2.3).

The passageways, though always narrow in width and low in height, can run as short as $1 \mathrm{~m}$ in length, as at the so-called 'Druid Stone' tomb in Ballintoy, Co. Antrim, or as long as $40 \mathrm{~m}$ in length, as at Knowth, Co Meath. Likewise, chamber size also varies from $1.2 \mathrm{~m}$ to $6.4 \mathrm{~m}$ in diameter and from $c .1 .6 \mathrm{~m}$ to $6 \mathrm{~m}$ in height. Also, while most assume simple circular, polygonal or sub-rectangular configurations in plan, more convoluted layouts which incorporate additional cells or side chambers are not uncommon (Waddell, 2010; Eogan and Cleary, 2017). Given that they are often found in close proximity to other such monuments, the term passage tomb cemetery is frequently used to denote the characteristic clustering of this particular tomb type.

\subsection{Brú na Bóinne}

Counted amongst "the greatest architectural achievements of megalith builders in western Europe" (Waddell 2010), the three 'mega-mounds' of Newgrange, Knowth and Dowth represent the most celebrated examples of the Irish passage tomb class due to their scale, the sophistication of the methods employed in their construction and the elaborate decoration that adorns many of the megaliths they comprise. They are located in the socalled Brú na Bóinne landscape of Co. Meath, an area which is bordered on three sides by the River Boyne and measures little more than $2 \mathrm{~km}$ in width and $5 \mathrm{~km}$ in length (Figure 3 )

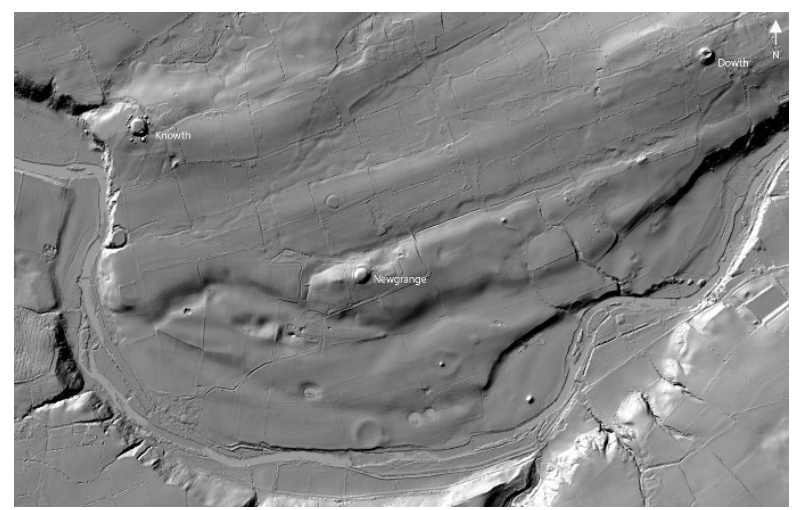

Figure 3. The results of an aerial LiDAR survey of the Boyne Valley, showing the three 'mega mounds' of Brú na Bóinne.CThe Discovery Programme, Meath County Council and The Heritage Council

Designated a UNESCO World Heritage Site in 1997, the landscape is home to at least 37 more passage tombs and some 60 other recognised monuments of various classes and dates, both prehistoric and historic, with an additional 125 sites provisionally identified over the last two decades based on aerial photography, LiDAR survey analysis, fieldwalking and geophysical prospection (Eogan and Cleary, 2017). Perhaps the most intriguing discovery in Brú na Bóinne in recent years, however, is that of the Dowth Hall passage tomb, which was uncovered in the summer of 2017 as part of a programme of archaeological monitoring and testing in advance of the restoration and conservation of Dowth Hall, a neo-classical Georgian villa set within the 430 acre Devenish Lands at Dowth estate.

\subsection{Dowth Hall}

Sited c.665m east-north-east of the renowned 'mega-mound' at Dowth, the Dowth Hall tomb lies buried beneath an artificially shaped terrace on top of which stands the mid- $18^{\text {th }}$ century villa (Figure 4).

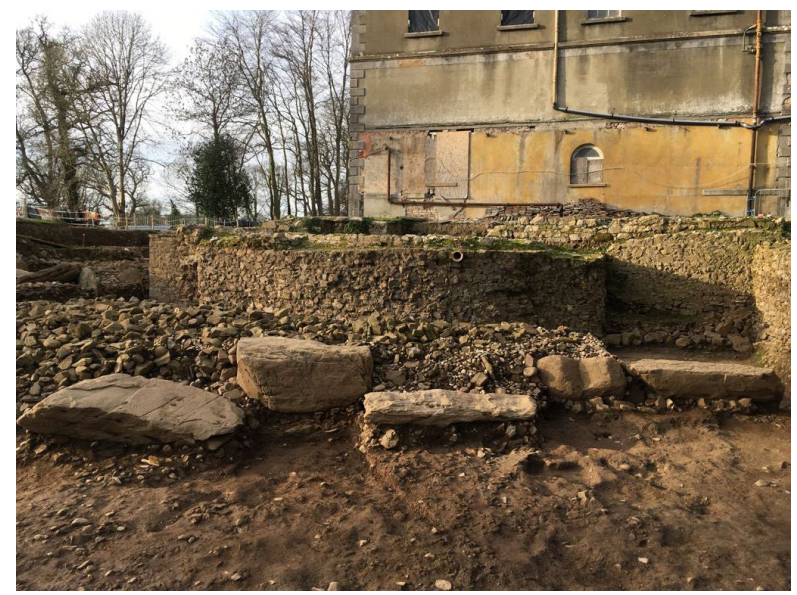

Figure 4. Shows the exposed remains of the tomb beneath the Hall.CLouise Callan

With two smaller, previously recorded tombs located c. $41 \mathrm{~m}$ to the west and c. $48 \mathrm{~m}$ to the south west, it appears to have been the focal mound of what was an unknown passage tomb cemetery in the area. That there exists no written record of this monument or local lore referencing its existence is of particular interest given that the builders of the Hall undoubtedly exposed it during the construction of the villa's basement and the two servants tunnels by which the basement was accessed. Indeed, later in the $19^{\text {th }}$ century, further construction work was carried out including the extension of the basement and the addition of a third tunnel which would, yet again, have brought the remains of the prehistoric tomb to light. The decision not to publicise its discovery was clearly a deliberate one, likely made for fear of inviting public pressure to relocate the house, the location of which appears to have been chosen specifically for the commanding views it affords across the Boyne Valley. Whatever the reason, the tomb unsurprisingly sustained significant damage as a result of these $18^{\text {th }}$ and $19^{\text {th }}$ century building works. What has survived, as revealed by a programme of targeted excavation, includes two megalithic chambers, part of a perimeter kerb and the lower courses of a much truncated stone cairn which was extensively quarried in the modern period to provide building materials for the construction of the Hall. Thus, while in its current state it reaches a maximum of $1.6 \mathrm{~m}$ in height, it is estimated that it may have stood c. 5-6 meters tall originally. Its diameter is likewise difficult to establish accurately, though it is estimated based on the arced trajectory of the remaining cairn to have measured c. $40 \mathrm{~m}$, making it roughly half the size of the neighbouring 'mega mound' (Ní Lionáin, 2021) (Figure 5). 


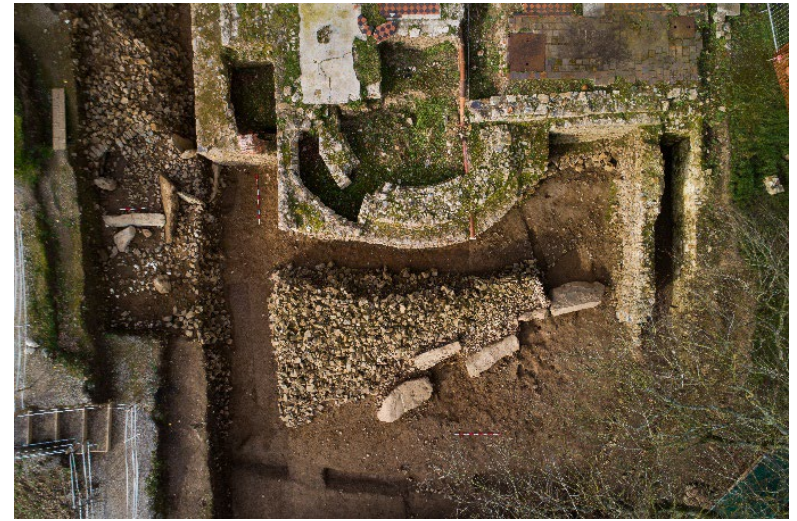

Figure 5. An aerial view showing the $18^{\text {th }}$ century basement and the later $19^{\text {th }}$ century extension and tunnel, with the partially exposed southern chamber to the west and exposed kerb and cairn remains to the south. CKen Williams

While both chambers are located in the western half of the cairn, one to the north and one to the south, they are morphologically distinct, with the northern chamber assuming a stalled configuration and its southern counterpart seemingly comprising a sub-circular arrangement, with at least one side chamber opening to the east. No upstanding evidence of corresponding passageways has yet been identified. However, disturbed megaliths in the vicinity of the northern chamber may represent the remains of an associated passage. Megalithic art has been identified in both chambers and on the kerb, the exposed remains of which comprises six kerbstones, five of which are contiguous. Kerbstone 2 (K2), which has slipped forward and is now lying in a supine position, is elaborately decorated across much of what was its outward facing surface (Figure 6).

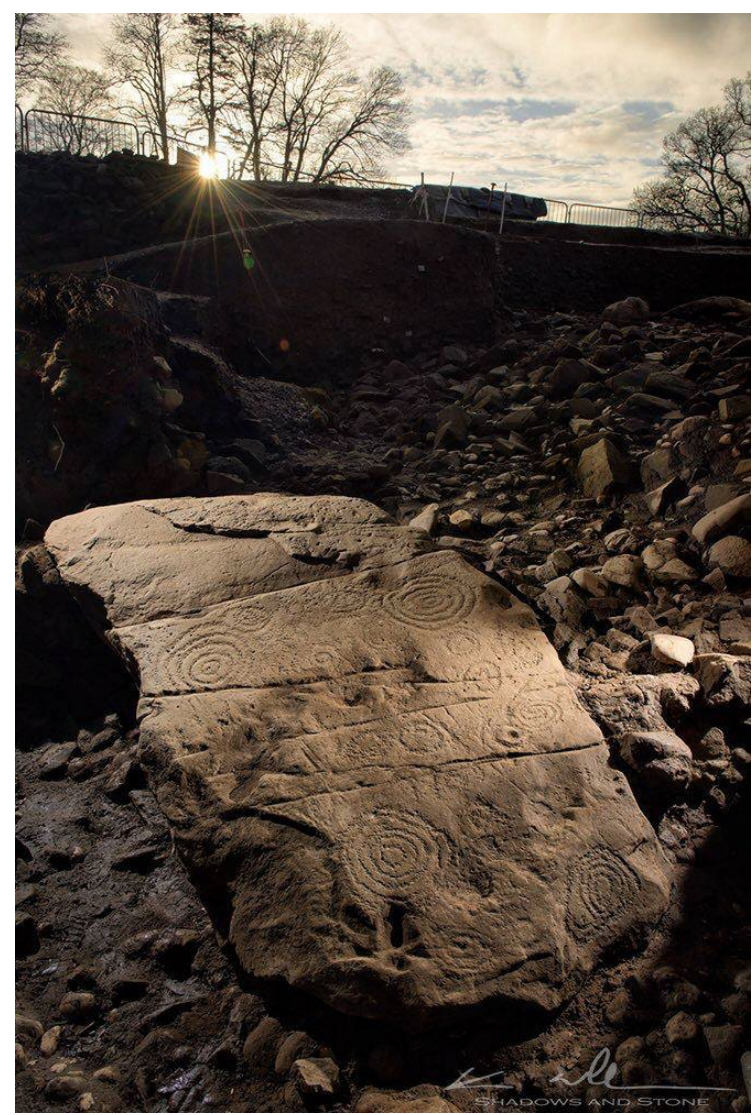

Figure 6. The richly carved surface of K2. CKen Williams

\section{METHODOLOGY AND RESULTS}

\section{1 iPad Pro LiDAR Survey}

Carried out on an overcast November afternoon, the iPad Pro LiDAR survey at Dowth Hall encompassed much of the site's excavated megalithic remains and part of the cairn (Figure 7). With a maximum range of $5 \mathrm{~m}$, the device's onboard scanner is not suitable for large-scale visualisation projects but was relatively well suited to the documentation of the exposed tomb given the increased access afforded by excavation. The very lightweight nature of the device, which tips the scales at $1.5 \mathrm{lbs}$, further lent itself to the recording of the complex architectural arrangement that comprises the remains of the northern chamber, allowing the sensor to be passed over this group of uprights in a dynamic and responsive manner. Using Laan Lab's 3D Scanner App, real time display of triangulation in the viewport also served as a useful tool in ensuring full coverage had been achieved before processing.


Figure 7. Textured meshes of a range of exposed structural stones from Dowth Hall, created using the iPad Pro in conjunction with the 3D Scanner App and MeshLab.

The entire operation was completed in less than 2 hours, with both chambers scanned during this time, together with the exposed kerb and its associated stretch of cairn. The data collected was then processed following the traditional workflow, moving from point cloud generation to surface meshing and onto texturing using the corresponding images. An associated editing tool also allowed for segmentation and cleaning of the mesh.

Like other software applications, a wide variety of file output formats are facilitated by 3D Scanner App, a number of which allow for further processing in Building Information Modelling (BIM) environments. In keeping with the approaches described here, employing a BIM workflow in the context of built heritage requires initial capture of geometry and texture-related data using laser scanning or digital photogrammetry. This is then followed by the conversion of the digital survey data to solid BIM models to allow for conservation, structural analysis and virtual reconstruction. The complex and non-uniform geometry that characterises the megalithic structures at Dowth Hall are, however, difficult to represent in 3D virtual environments. Thus, in a bid to overcome this problem, segmentation of the LiDAR meshes has been carried out to isolate individual components and develop a shape ontology of the recorded stones which can then be used in various reconstruction scenarios (Figures 8a and 8b). 



Figures $8 \mathrm{a}$ (above) and $8 \mathrm{~b}$ (below). Ortho projections from the untextured LiDAR-generated meshes allow for HBIM analysis of stone positioning and alignment.

\subsection{Artec Leo Survey}

Some weeks after the iPad Pro survey, in early December, the elaborately decorated K2 was again scanned using an Artec Leo hand-held structured light scanner (Figure 9) (https://cdn.artec3d.com/pdf/Artec3D-Leo.pdf). Scanning took place on a bright sunny morning, with the lighting and shadows controlled to an extent by the use of plastic sheeting. The instrument was set to scan on HD mode, with the surface of the stone recorded using 3 separate scans to maximise coverage from different directions. The onboard real-time processing and display of remaining gaps further supported this in ensuring as complete a surface as possible. Completed within approximately thirty minutes, including time taken to assess the stone and plan a scanning strategy, this approach was both time and energy efficient. A remarkably ergonomic instrument, the Artec Leo's power supply, initial processing and data storage are all incorporated, with no laptop connection or portable generator required. This wireless configuration makes it far easier to operate than other scanners such as the Artec Eva, with no cables to restrict movement. It is also more tolerant of the ambient lighting conditions, successfully recording K2 in difficult low winter sunlight.

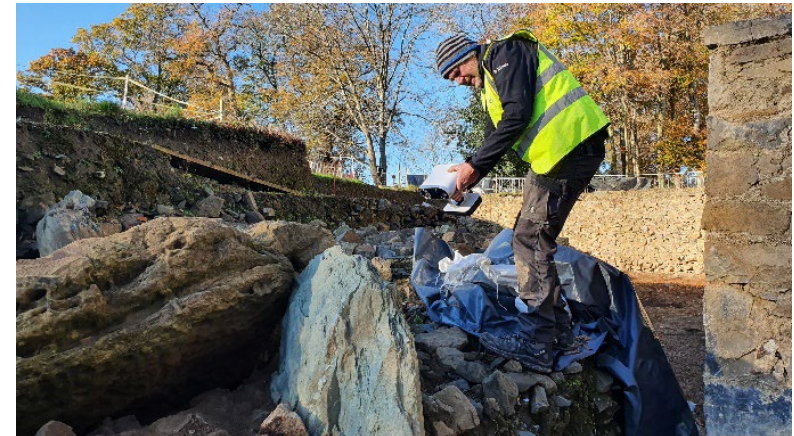

Figure 9. The Artec Leo in action at a Dowth Hall, capturing a decorated upright in the southern chamber.

Although HD settings were enabled during scanning, both SD and HD versions of the scanned data can be and were downloaded. In the case of $\mathrm{K} 2$, these were processed following the auto-pilot processing path in Artec Studio 16 Professional software, (Figure 10), which involved registration (fine and global), fusion (outlier removal, sharp fusion) and some postprocessing (small-object filtering). Finally, a texture was generated from the scan images.

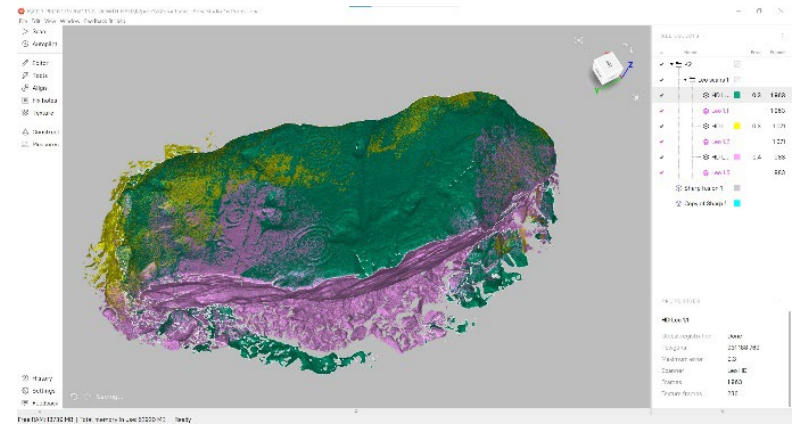

Figure 10. A screen capture of the scan data in Artec Studio 16. The colours indicate the areas covered by each of the three scans.

The mesh models generated using both SD and HD processing are impressive $3 \mathrm{D}$ records of the stone surface, with no significant difference observed on initial visual inspection, at complete stone level (Figures 11a and 11b).



Figure 11a. 3D mesh model generated using SD data (3.7 million polygons). 


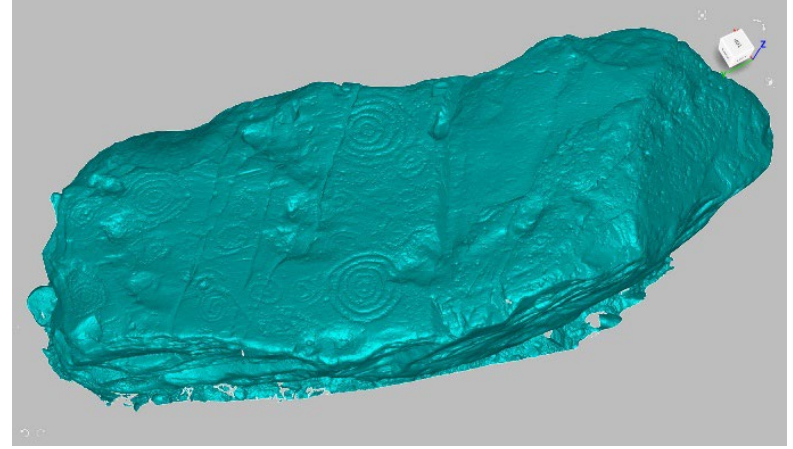

Figure $11 \mathrm{~b}$. 3D mesh model generated using HD data (62 million polygons).

However, closer inspection revealed a considerably improved level of detail in the HD model (Figures 12a and 12b). This disparity is to be expected given the polygon counts involved, with the HD version comprising 85 million polygon compared to the SD's 3.7 million, but the former inevitably comes at a considerable cost in hardware requirements, data transfer and processing time. The method to generate a photorealistic texture from the HD data, furthermore, has yet to be successfully completed, and this remains a significant issue. The photo texture from SD processing (Figure 13) was successfully generated, but an initial inspection suggests it is not as high quality as photogrammetrically generated textures. The impact of the low sunlight and shadows can be seen as pink/red hues around the edge of the stone.

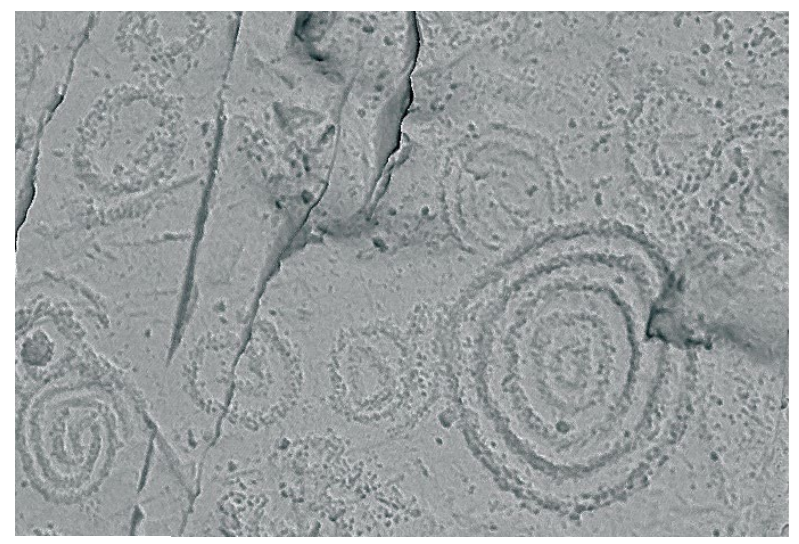

Figure 12a. A radiance scaling visualisation of a section of the SD model generated in MeshLab.

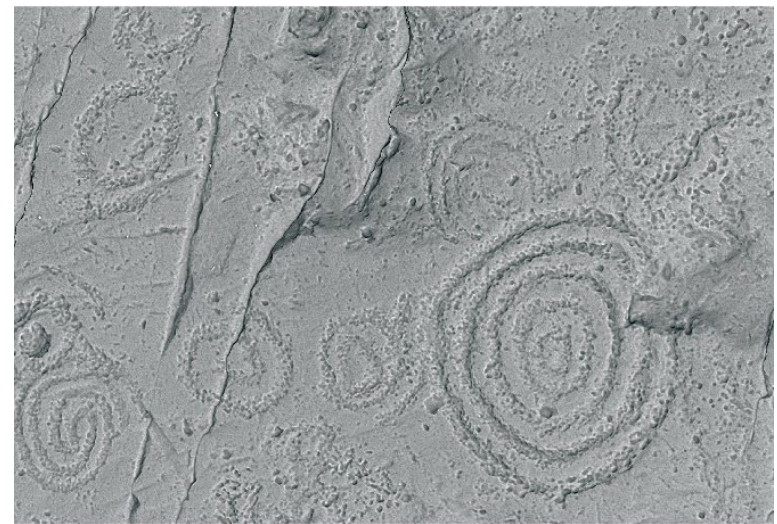

Figure $12 \mathrm{~b}$. A similarly generated radiance scaling visualisation of the same section of the HD model, showing clear improvement in the resolution and resultant sharpness of feature definition.

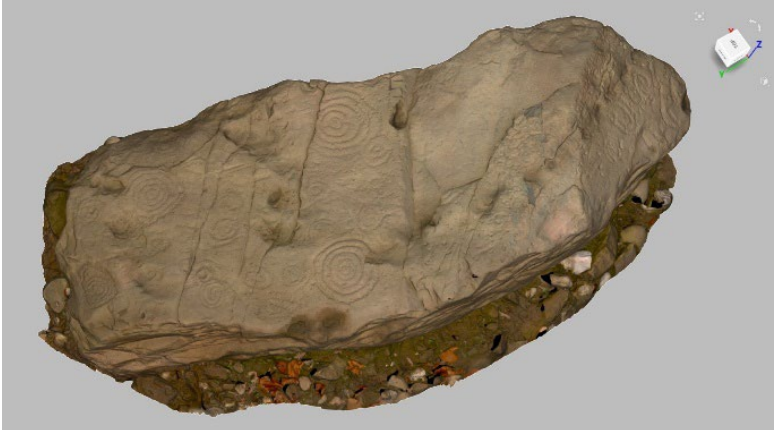

Figure 13. A photo-textured 3D mesh model generated using SD data

\subsection{Photogrammetric Survey}

On completion of the scanning operation detailed in the previous section, $\mathrm{K} 2$ was also digitally documented, on the same day, by means of a photogrammetric survey, the images for which were captured onsite using a Canon 6D MkII full frame camera with a $50 \mathrm{~mm}$ prime lens in Canon RAW format. Before taking any photographs, two photogrammetric scales were positioned next to the object to ensure that any derived model would be created at the correct scale, with an image of the stone including an X-Rite ColorChecker Passport Photo 2 colour calibration target also recorded to likewise ensure that any photographic texture was accurate (Figure 14).

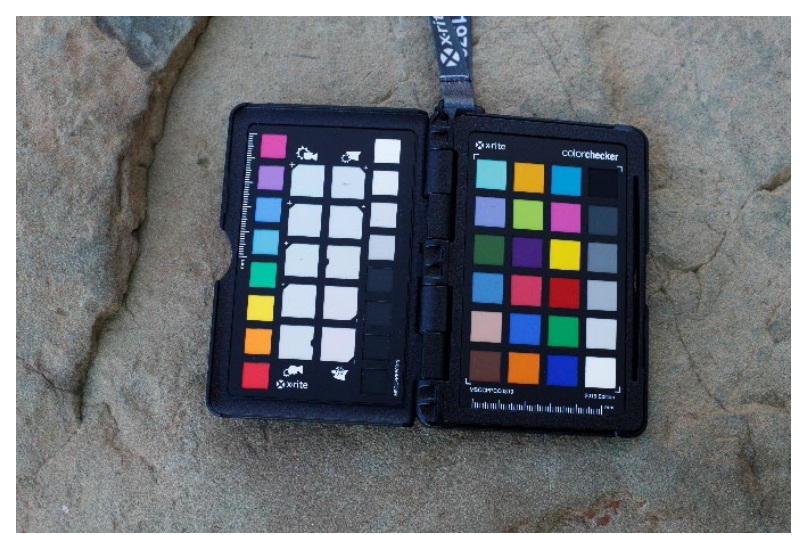

Figure 14. The X-Rite ColorChecker Passport Photo 2 colour calibration image.

In total, 364 images were captured following several orbits around the stone to ensure a high level of image overlap and surface coverage from as many orientations as possible. Image capture on site took approximately 10 minutes and additional shading was required due to the effect of direct sunlight producing harsh shadows. Initial processing of the original RAW images was carried out in Adobe Bridge where two image datasets were created:

1. A series of images adjusted using the X-Rite ColorChecker image to generate a colour profile for the survey that ensures accuracy in the colour and tonal depth of the stone. This image set was used to texture the final 3D model.

2. A series of images adjusted to ensure high levels of image contrast and tonal variation to aid in photogrammetric pixel matching process.

Photogrammetric processing was completed using RealityCapture (Ver 1.2.0.03813) software where, following the process of image alignment, a high resolution mesh model was 
created (62.5 million polygons). This model was subsequently cleaned by removing unwanted parts of the mesh at the edge of the survey area before the topological integrity was checked to ensure that there was no holes or overlapping polygon faces. Finally, the model was simplified to 30 million polygons to enable its successful rendering in the relevant visualization software (Figures 15 and 16). The total processing time was 23 minutes.

In addition to the high-resolution mesh model, a lower resolution version of the stone was also created $(300,000$ polygons). A series of texture maps were generated (Normal, ambient occlusion, cavity, calibrated photo texture, roughness) for this model using a range of software (3DS Max, Substance painter, XNormal) which enable the effective visualisation of the stone through online platforms (e.g. Sketchfab) and the creation of real time renders and images utilising Marmoset Toolbag.

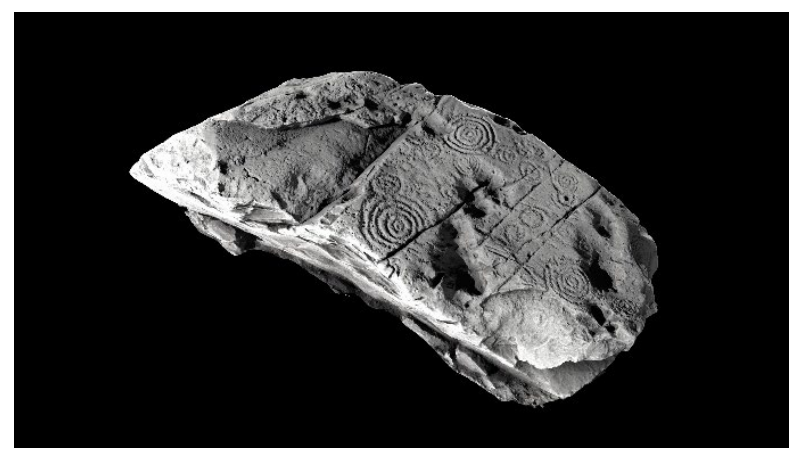

Figure 15. A rendered image of the K2 model generated in RealityCapture with procedurally generated texture.

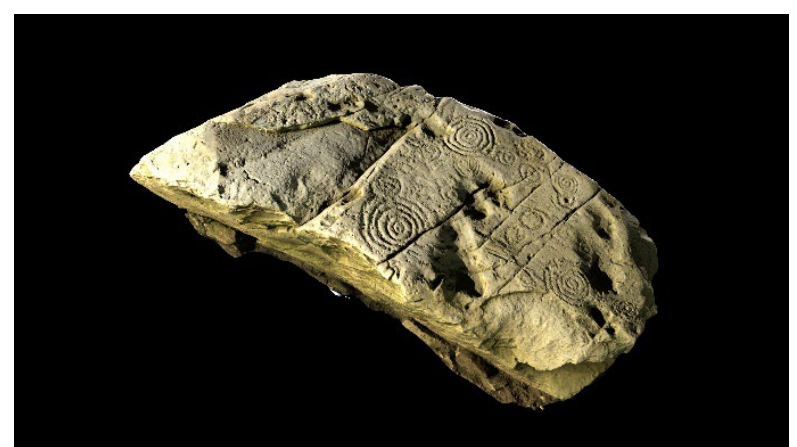

Figure 16. A rendered image of the $\mathrm{K} 2$ model generated in RealityCapture with calibrated colour photo texture and illumination to highlight artwork.

\section{CONCLUSION}

It is clear that the accuracy, quality and detail achieved using both photogrammetric technology and the Artec structure from light scanner is superior to that achieved using the lower cost iPad sensor. However, as detailed in section 3.1, the conversion of the LiDAR data into BIM objects involves a simple but potentially powerful workflow, and it is perhaps in this context that the value of the low-cost sensor and its associated software applications can best be appreciated. The output generated in this way can, furthermore, be combined with that of the more accurate and higher quality surveys, and ultimately integrated within a Historic BIM/GIS thus creating larger digital ensembles that can be used to carry out a wide range of analyses and to explore various digital reconstruction scenarios.

\subsection{Future Work - Reconstruction Scenarios}

While the targeted excavations at Dowth Hall have exposed some megaliths in their entirety, others remain only partially exposed, with one or more of their faces inaccessible. Future work in this area will involve the modelling of synthetic objects which represent the missing structural elements. These synthetically generated objects can then be combined with recorded mesh objects to allow for the exploration of various reconstruction scenarios. In addition, associated data (historic, engineering, materials etc.) can also be embedded within the objects including the assignment of real values to the parameters and other required data (Figure 17).

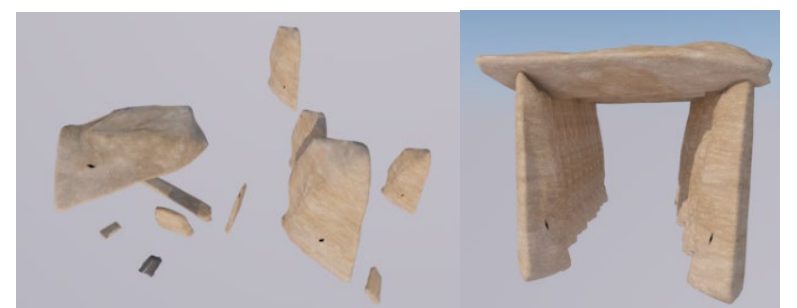

Figure 17. An ontology of synthetic megaliths (left) and hypothetical passage tomb reconstruction scenario involving passageway orthostats and lintels (left)

\subsection{Closing Note}

Finally, the research outputs presented in this paper represent the first stage in the development of a dedicated virtual documentation, analysis and modelling framework for Dowth Hall (Figure 18). The potential value of such a framework extends across the fields of conservation, material analyses and archaeological interpretation, with possible avenues of dissemination including VR and AR as well as traditional nonimmersive presentation via game engine platforms.

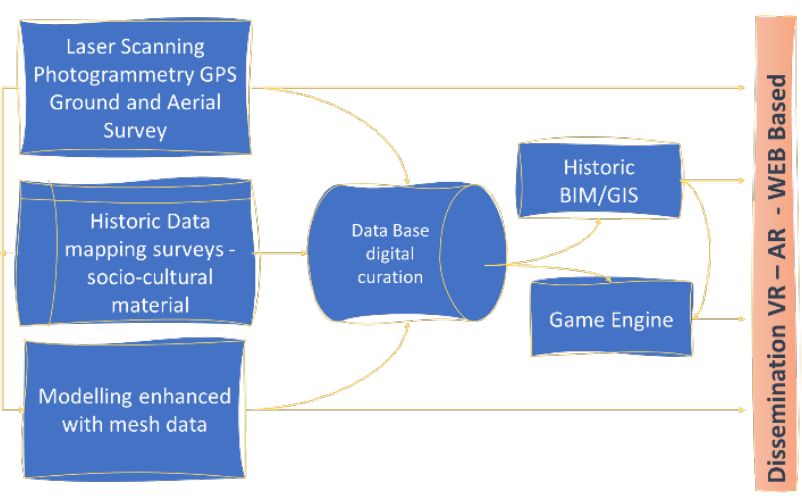

Figure 18. A virtual documentation, analysis and modelling framework for the visualisation and presentation of built heritage.

\section{ACKNOWLEDGEMENTS}

Many thanks to the Heritage Council, Meath County Council, Louise Callan, and Ken Williams for allowing the use of the copyrighted images included here.

\section{REFERENCES}

Cerillo-Cuenca, E., de Sanjosé Blasco, J.J., Bueno-Ramírez, P., Perez-Álvarez, J.A., de Balbín Behrmann, R. and SánchezFernández, M., 2021. Emergent heritage: the digital conservation of archaeological sites in reservoirs and the case of 
the Dolmen de Guadalperal (Spain). Heritage Science Vol 9(114). DOI: 10.1186/s40494-021-00590-5

Corns, A. and Shaw, R. 2013. LiDAR and World Heritage Sites in Ireland: why was such a rich data source gathered, how is it being utilised, and what lessons have been learned? In R. S. Opitz and D.C.C. Cowley (eds), Interpreting Archaeological Topography. Airborne Laser Scanning, 3D Data and Ground Observation. Oxford: Oxbow, pp.146-160.

Davis, S., Megarry, W., Brady, C, Lewis, H., Cummins, T., Guinan, L. Turner, J. Gallagher, C., Brown, T. and Meehan, R., 2010. Boyne Valley Landscapes Project. Phase III Summary Report. Dublin: The Heritage Council.

Davis, S., Strange-Walker, D. and Abbott, M., 2012. Laser scanning at Brú na Bóinne. Archaeology Ireland, Vol 26(3), pp. 13-15.

Davis, S. Brady, C., Megarry, W. and Barton, K., 2013. Lidar survey in the Brú na Bóinne World Heritage Site. In R. S. Opitz and D.C.C. Cowley (eds), Interpreting Archaeological Topography. Airborne Laser Scanning, 3D Data and Ground Observation. Oxford: Oxbow, pp.225-239.

El-Hakim, S., Beraldin, J.-A., Remondino, F., Picard, M., Cournoyer, L., and Baltsavias, M., 2008. Using Terrestrial Laser Scanning and Digital Images for 3D Modeling of the Erechteion, Acropolis of Athens. Proceedings of the Digital Media and its Applications in Cultural Heritage (DMACH 2008). 3-6 November 2008. NRC 50721

Eogan, G. and Cleary, K. (eds), 2017. The Passage Tomb Archaeology of the Great Mound at Knowth. Excavations at Knowth 6.Dublin: Royal Irish Academy.

Megarry, W. and Davis, S. 2013. Beyond the bend: remotely sensed data and archaeological site prospection in the Boyne Valley, Ireland. In Comer, D.C. and Harrower, M.J. (eds), Mapping Archaeological Landscapes from Space. New York: Springer, pp. 85-96. DOI: 10.1007/978-1-4614-6074-9_8.

Ní Lionáin, C., 202. Preliminary Report (17E0242). Phase 1 Excavation and Phase $2 a$ Testing Programme at Dowth Hall, Co. Meath. Unpublished report.

Remondino, F., Del Pizzo, S., Kersten, T., Troisi, S., 2012. Low-cost and open-source solutions for automated image orientation - A critical overview. Proc. EuroMed 2012 Conference, LNCS Vol. 7616, pp. 40-54. DOI: 10.1007/978-3642-34234-9_5

Waddell, J., 2010. The Prehistoric Archaeology of Ireland. Dublin: Wordwell.

3D Icons, 2015. Brú na Bóinne, http://www.3dicons.ie/3dcontent/bru-na-boinne (Last accessed: Nov 2021). 